\title{
High-Resolution Genomic Analysis of the 11q13 Amplicon in Breast Cancers Identifies Synergy with 8p12 Amplification, Involving the mTOR Targets S6K2 and 4EBP1
}

Elin Karlsson, Marie Ahnström, Josefine Bostner, Gizeh Perez-Tenorio, Birgit Olsson, Anna-Lotta Hallbeck and Olle Stål

\section{Linköping University Post Print}

N.B.: When citing this work, cite the original article.

This is the authors' version of the following article:

Elin Karlsson, Marie Ahnström, Josefine Bostner, Gizeh Perez-Tenorio, Birgit Olsson, AnnaLotta Hallbeck and Olle Stål, High-Resolution Genomic Analysis of the 11q13 Amplicon in Breast Cancers Identifies Synergy with 8p12 Amplification, Involving the mTOR Targets S6K2 and 4EBP1, 2011, Genes, Chromosomes and Cancer, (50), 10, 775-787.

which has been published in final form at:

http://dx.doi.org/10.1002/gcc.20900

Copyright: Wiley-Blackwell http://eu.wiley.com/WileyCDA/Brand/id-35.html

Postprint available at: Linköping University Electronic Press http://urn.kb.se/resolve?urn=urn:nbn:se:liu:diva-70514 
High-resolution genomic analysis of the $11 q 13$ amplicon in breast cancers identifies synergy with 8p12 amplification, involving the mTOR targets S6K2 and 4EBP1

Elin Karlsson, Marie Ahnström Waltersson, Josefine Bostner, Gizeh Pérez-Tenorio, Birgit Olsson, Anna-Lotta Hallbeck and Olle Stål

\section{Authors' affiliations}

Department of Clinical and Experimental Medicine, Division of Oncology, Faculty of Health Sciences, Linköping University, Linköping, Sweden

\section{Corresponding author}

Elin Karlsson, Department of Clinical and Experimental Medicine, Division of Oncology, Faculty of Health Sciences, Linköping University, SE-581 85 Linköping, Sweden. Phone: +46 010 1038117; Fax: +46 013-127465; e-mail: elin.karlsson@liu.se

This study was supported by grants from the Swedish Cancer Foundation and the Swedish Research Council.

\section{Running title}

$11 \mathrm{q} 13$ amplification in breast cancer 


\section{Abstract}

The chromosomal region 11q13 is amplified in 15-20\% of breast cancers; an event associated with oestrogen receptor (ER) expression but also implicated in resistance to endocrine therapy. Coamplifications of the $11 \mathrm{q} 13$ and $8 \mathrm{p} 12$ regions are common, suggesting synergy between the amplicons. The aim was to identify candidate oncogenes in the 11q13 region based on recurrent amplification patterns and correlations to mRNA expression levels. Furthermore, the 11q13/8p12 coamplification and its prognostic value, was evaluated at the DNA and the mRNA levels. Affymetrix $250 \mathrm{~K} N s p \mathrm{I}$ arrays were used for whole genome screening of DNA copy number changes in 29 breast tumours. To identify amplicon cores at $11 \mathrm{q} 13$ and 8p12, Genomic Identification of Significant Targets in Cancer (GISTIC) was applied. The mRNA expression levels of candidate oncogenes in the amplicons (RAD9A, RPS6KB2 (S6K2), CCND1, FGF19, FGF4, FGF3, PAK1, GAB2 (11q13); EIF4EBP1 (4EBP1), PPAPDCIB and FGFR1 (8p12)) were evaluated using real-time PCR. Resulting data revealed three main amplification cores at 11q13. ER expression was associated with the central 11q13 amplification core, encompassing CCND1, whereas 8p12 amplification/gene expression correlated to $S 6 K 2$ in a proximal $11 \mathrm{q} 13$ core. Amplification of 8p12 and high expression of $4 E B P 1$ or FGFRl was associated with a poor outcome in the group. In conclusion, SNP arrays have enabled mapping of the 11q13 amplicon in breast tumours with high resolution. A proximal 11q13 core including $S 6 K 2$ was identified as involved in the coamplification/coexpression with 8p12, suggesting synergy between the mTOR targets S6K2 and 4EBP1 in breast cancer development and progression. 


\section{Introduction}

Genetic and epigenetic alterations are fundamental characteristics in the development of malignancy. The chromosome band 11q13 is amplified in a significant proportion of cancers, including 15-20\% of breast cancers (Borg et al., 1991; Karlseder et al., 1994; Schuuring, 1995; Courjal et al., 1997; Al-Kuraya et al., 2004). Amplification of this region has been reported also in benign and in situ lesions of the breast (Weinstat-Saslow et al., 1995; Simpson et al., 1997; Alle et al., 1998), suggesting that this is an early event, connected to initiation of carcinogenesis, rather than a secondary effect of genomic instability. Several studies have indicated a clinical significance of the 11q13 amplicon, but its complex amplification patterns and the fact that the region is extremely gene dense have obstructed a definite identification of driving oncogenes. To date, CCND1, encoding the cell cycle regulator Cyclin D1, is by far the most extensively studied candidate oncogene in this area in breast cancer. However, it has been suggested that the region harbours several independent amplification cores, indicating additional driving oncogenes (Ormandy et al., 2003). In the first detailed study of 11q13 amplifications in breast cancer, 389 carcinomas were screened for amplification status of ten molecular markers, which identified four independent amplification cores around D11S97 (62 Mb), CCND1 (69.5 Mb), EMS1 (70 Mb) and D11S833E (76-77Mb) (Karlseder et al., 1994). These areas were further confirmed as independent amplicons by Southern blot, real-time PCR and comparative genomic hybridization (CGH) (Bekri et al., 1997; Courjal et al., 1997; Hui et al., 2002; Rodriguez et al., 2004). In a recent study, 18 breast tumours with 11q13 amplification were screened using array CGH with 101 BAC clones covering the 11q12-14 area (Kwek et al., 2009). The study revealed an even more complex amplification pattern, with several separated areas of amplification. However, minimal areas of amplification could be condensed into five cores (around 69.5 Mb, 70.0 Mb, 76.2 Mb. 76.5 Mb and 77.1 Mb). 
$11 \mathrm{q} 13$ amplification has been correlated to positive oestrogen receptor (ER) status in breast tumours (Letessier et al., 2006; Elsheikh et al., 2008). Due to the availability of antioestrogen therapies, ER positivity is considered as a marker of good prognosis. However, among patients with ER positive tumours, those also harbouring 11q13 amplification seem to constitute a subgroup with higher grade and a relatively poor prognosis (Al-Kuraya et al., 2004). A possible explanation is a connection between the amplicon and endocrine resistance, which has been implicated in both in vitro (Wilcken et al., 1997; Bindels et al., 2002; Hui et al., 2002) and in clinical studies (Kenny et al., 1999; Stendahl et al., 2004; Ahnström et al., 2005; Jirström et al., 2005; Holm et al., 2006; Bostner et al., 2007; Rudas et al., 2008).

Several studies have demonstrated that the $11 \mathrm{q} 13$ region is commonly coamplified with regions at 8p11-12 (Cuny et al., 2000; Letessier et al., 2006). The presence of both of these amplifications seems to predict a worse patient outcome than either amplicon alone, suggesting a synergy where potential oncogenes remain to be elucidated (Cuny et al., 2000).

In the present study, whole-genome single nucleotide polymorphism (SNP) arrays were used to perform a comprehensive analysis of copy number alterations in breast tumours harbouring amplification in the 11q13 region and to map this area with high resolution. By using the statistical approach Genomic Identification of Significant Targets In Cancer (GISTIC) (Beroukhim et al., 2007), three main amplicon cores at 11q13 could be identified. The mRNA levels of candidate oncogenes in these hotspots were evaluated using quantitative real-time PCR. Among recurrent genome-wide copy number alterations, amplification in the 8p12 region was most frequently found. This connection was evaluated at DNA and mRNA levels and the results suggest a prognostic significance of $11 \mathrm{q} 13 / 8 \mathrm{p} 12$ coamplification and coexpression. Furthermore, coamplification was found to frequently engage the amplicon cores including the mTOR targets S6K2 and 4EBP1. 


\section{Materials and methods}

\section{Patients}

The study comprised a tumour material of 34 breast tumours with 11q13 amplification, selected from a cohort of 185 breast tumours from postmenopausal patients with stage II breast cancer. 11q13 positivity was defined as four or more gene copies of CCND1 (encoding Cyclin D1) and/or PAK1 (encoding p21-activated kinase 1) and/or RPS6KB2 (S6K2, encoding S6 kinase 2) (Bostner et al., 2007; Perez-Tenorio et al., 2010). From these, 29 were available for DNA extraction and array analysis, and 23 (whereof 21 included in the array analysis) were available for RNA extraction and real-time PCR. All samples were histologically estimated to contain at least $50 \%$ malignant cells.

\section{DNA and RNA extraction}

Genomic DNA was extracted from fresh-frozen tumour tissue using the Puregene ${ }^{\circledR}$ DNA purification kit (Gentra, Minneapolis, MN, US) according to the manufacturer's instructions. Briefly, the tissue was digested in proteinase- $\mathrm{K}$ solution, $55^{\circ} \mathrm{C}$, until totally dissolved after approximately 4-5 days. The cell lysate was treated with RNase, for $15 \mathrm{~min}$, at $37^{\circ} \mathrm{C}$. Proteins were precipitated using protein precipitation solution and pelleted by centrifugation $\left(16000^{*} \mathrm{~g}\right.$, 3 min, room temperature). The supernatant was collected and DNA was precipitated with isopropanol and pelleted by centrifugation $\left(16000^{*} \mathrm{~g}, 1 \mathrm{~min}\right.$, room temperature). Finally, DNA was washed with $70 \%$ ethanol, dried in air and dissolved in sterile water for storage at $70^{\circ} \mathrm{C}$. DNA concentration was measured using a NanoDrop ND-1000 Spectrophotometer (Nanodrop Technologies, Wilmington, DE, US). DNA quality, referred to as minimum degradation, was assessed by running the samples on a $1 \%$ agarose gel for $30-60$ minutes, using genomic DNA 103, included in the Affymetrix 250K Nsp kit, as a positive control for intact DNA. 
Of the 11q13 positive samples initially included in the study, 23 were available for RNA extraction, whereof 21 were included in the array analysis. Fresh frozen tumour tissue was homogenised with a microdismembrator (B Braun, Melsungen, Germany) and total RNA was isolated using the mirVana ${ }^{\mathrm{TM}}$ miRNA Isolation kit (Ambion, Austin, TX, USA), according to manufacturer's recommendations. Purified RNA was eluted in nuclease-free water and RNasin ${ }^{\circledR}$ Ribonuclease Inhibitor (Promega, WI, USA) was added before storage at $-70^{\circ} \mathrm{C}$. RNA quantity and quality was assessed with an Agilent 2100 Bioanalyzer (Agilent Technologies, Santa Clara, CA, US).

\section{SNP arrays and data analysis}

Affymetrix $250 \mathrm{~K}$ NspI arrays were used to profile the 29 tumour samples for whole genome DNA copy number changes. The assay was performed according to the Affymetrix recommended protocol (Affymetrix, Santa Clara, CA, US). Briefly, $250 \mathrm{ng}$ of total genomic DNA was digested with $N s p$ I, ligated to adaptors and PCR amplified using adaptor specific primers. The purified PCR products were fragmented, labelled with biotin and hybridised to the arrays. Affymetrix Scanner $30007 \mathrm{G}$ was used to scan the arrays and generated data were converted to cell intensity files in GeneChip ${ }^{\circledR}$ Operating Software (GCOS). Cell intensity data were processed by Affymetrix GeneChip ${ }^{\circledR}$ Genotyping Analysis Software (G-TYPE) 4.1. The BRLMM algorithm was applied for data normalisation and generation of genotype calls for each SNP in each sample. Resulting data was utilised for copy number analysis with the Copy Number Analysis Tool (CNAT) 4 algorithm as follows. Briefly, the relative copy number of each SNP was primarily estimated by calculating the log2ratio of the normalised signals; $\log 2$ $\left(\mathrm{S}_{\text {sample }} /\right.$ mean $\mathrm{S}_{\text {ref }}$ ), where 30 female samples from the HapMap project (available at www.Affymetrix.com) were used as references. To reduce the level of noise and to capture important patterns in the data, Gaussian smoothing was performed on the log2ratios, using the 
default bandwidth of $100 \mathrm{~kb}$. Copy number state (CNstate) for the SNPs were estimated by applying a Hidden Markov Model (HMM), using default parameters in the software, where five hidden states represent the following copy number aberrations; homozygous deletion $(\mathrm{CNstate}=0)$, hemizygous deletion $(\mathrm{CNstate}=1)$, copy neutral $(\mathrm{CN}$ state $=2)$, single copy gain $(\mathrm{CNstate}=3)$, and amplification $(\mathrm{CNstate}=4)$. Gene copy number was also expressed as a continuous variable by calculating $2^{\wedge}(\log 2$ ratio+1) for each SNP. Resulting data was visualised by CNATviewer and Affymetrix Genotyping Console (GTC) Browser. The NCBI tool MapViewer was applied for mapping of known genes within regions of gains and losses, whereby positions of genes were received from the Human genome build 36, ver3.

\section{Quantitative real-time PCR}

RNA was reverse transcribed into cDNA using the high-capacity cDNA reverse transcription kit (Applied Biosystems, Stockholm, Sweden), following the manufacturer's instructions. For each reaction, $200 \mathrm{ng}$ RNA was added to a final reaction volume of $20 \mu \mathrm{l}$. mRNA levels for RAD9A, S6K2, CCND1, FGF19, FGF4, FGF3, PAK1, GAB2, EIF4EBP1 (4EBP1), PPAPDC1B and FGFRl were measured in the 23 samples as previously described, using quantitative fast real-time PCR. TaqMan ${ }^{\circledR}$ assays were ordered as assay-on-demand with the exception of FGF4 for which primers and probes were designed using Primer Express v1.5a (Applied Biosystems) (Table 1). Real-time PCR was performed using TaqMan ${ }^{\circledR}$ Fast Universal PCR Master Mix (Applied Biosystems) in reactions of $10 \mu 1$. TaqMan ${ }^{\circledR}$ assays were diluted according to manufacturer's instructions, whereas a final concentration of $0.2 \mu \mathrm{M}$ were used for FGF4 primers and probes. TaqMan ${ }^{\circledR}$ chemistry was performed on an ABI Prism 7900ht (Applied Biosystems) using the default thermal program: $95^{\circ} \mathrm{C}$ for $20 \mathrm{~s}$, followed by 40 cycles of $95^{\circ} \mathrm{C}$ for $1 \mathrm{~s}$, and $60^{\circ} \mathrm{C}$ for $20 \mathrm{~s}$. The expression of FGF3, FGF4 and FGF19 was low in most samples. To increase the sensitivity of these assays; a preamplification step was performed in which the thermal program: $95^{\circ} \mathrm{C}$ for $60 \mathrm{~s}$, followed 
by 15 cycles of $95^{\circ} \mathrm{C}$ for $1 \mathrm{~s}$, and $60^{\circ} \mathrm{C}$ for $20 \mathrm{~s}$, was run in a Peltier Thermal Cycler (PTC200, MJ research) for each sample. Relative expression of each gene was calculated using the standard curve method, with $A C T B$ as an endogenous control (Table 1). Briefly, standard curves were constructed with four-fold serial dilutions of cDNA from the following cell lines: SKBR3 (S6K2, CCND1, PAK1, GAB2, 4EBP1 and FGFR1), HCT-116 (RAD9A and PPAPDC1B) and SW613-S; kindly provided by Olivier Brison, Curie Institute, Paris, France (FGF19, FGF4 and FGF3). Standard curves were included on each plate for genes of interest as well as for the endogenous control. All samples were run in triplicates and the median Ctvalues were used to calculate a relative expression value $(\mathrm{C})$ for each gene, based on the respective standard curve. Final mRNA quantitation was performed by calculating the ratio (C gene of interest/C endogenous control) for each sample.

Gene copy number analysis of $C C N D 1, P A K 1$ and $S 6 K 2$ by real-time PCR have been described elsewhere (Bostner et al., 2007; Perez-Tenorio et al., 2010)

Table 1 TaqMan ${ }^{\circledR}$ assays used for mRNA quantification by fast real-time PCR

\begin{tabular}{l|l}
\hline Gene & Assay (Applied Biosystems) \\
\hline$A C T B$ & Part no 4310881E \\
RAD9A & Hs00270240_m1 \\
RPS6KB2 & Hs00177689_m1 \\
CCND1 & Hs00765553_m1 \\
$F G F 19$ & Hs00192780_m1 \\
FGF3 & Hs01104462-m1 \\
FGF4 & Forward:5'-AGCAAGGGCAAGCTCTATG \\
& Reverse:5'-GTTGTTGGGAAGGAGAATCTCCT \\
PAK1 & Probe: 5'-FAM-TCGCCCTTCTTCACCGATGAGTGC-TAMRA \\
GAB2 & Hs00176815_m1 \\
EIF4EBP1 & Hs00373045_m1 \\
$P P A P D C 1 B$ & Hs00607050_m1 \\
FGFR1 & Hs00261167_m1 \\
\hline
\end{tabular}




\section{Evaluation of ER and ERBB2 status}

ER concentration was assessed in clinical routine by isoelectric focusing or enzyme immunoassay (EIA) at the time of diagnosis (Wrange et al., 1978), and these results are highly comparable with present-day immunohistochemistry data (Khoshnoud et al., 2010). ERBB2 protein expression was quantified using flow cytometry (Stål et al., 1994), whereas ERBB2 gene copy number was determined by real-time PCR (Gunnarsson et al., 2003).

\section{Statistical analyses}

To give a comprehensive view of the 11q13 amplification patterns across all samples and identify regions of significant aberrations, the principles of a statistical approach referred to as Genomic Identification of Significant Targets in Cancer (GISTIC) was applied (Beroukhim et al., 2007). GISTIC methodology is based on the assumption that the frequencies of occurrence, and to a greater extent the amplitude of the aberrations, are corner stones in the development of functionally important genomic changes. G-scores were calculated for each SNP across all samples for both gains and deletions according to:

$$
\begin{aligned}
& G^{\text {gain }}=F^{\text {gain }} \times \overline{C_{\text {gain }}} \\
& G^{\text {del }}=F^{\text {del }} \times \overline{C^{\text {del }}}
\end{aligned}
$$

where $F$ represents the frequency of an aberration and $\bar{C}$ its average amplitude. The threshold for gain was set to a CNstate $\geq 3$ and deletion CNstate $<2$. G-scores are plotted against chromosomal position and resulting peaks of maximal amplitude are indicative of regions harbouring driving oncogenes.

Spearman's Rank Order correlation was applied for assessing the correlation between gene copy number and mRNA expression level as well as between FGFR1 mRNA and ERBB2 protein expression. Multiple linear regression analysis was used for evaluating the 
correlations between the different amplification cores at 11q13, and ER expression respectively FGFR1 gene copy number. ER expression values were calculated as $\log 10(\mathrm{x}+1)$ in order to achieve a distribution close to normal. The Kaplan-Meier product limit method was used to estimate the cumulative survival probability in a patient group. Differences in survival between groups were evaluated with a log-rank test. All statistical analyses were performed with Statistica 9.1 (Statsoft Inc, Tulsa, OK, US). The criterion for statistical significance was $P<0.05$.

\section{Results}

Genome-wide copy number profiles of 11q13 amplified breast tumours

DNA copy number alterations were analysed on a genome wide scale in 29 breast tumours with 11q13 amplification. Using the definitions described by Hicks and colleagues (Hicks et al., 2006), 25/29 samples (86\%) belonged to a copy number profile referred to as "firestorm", that is one or a few regions of clustered, narrow peaks of high level amplification, with the remaining genome containing mainly simple alterations with duplications or deletions comprising entire chromosomes or chromosome arms. In 2/29 (7\%) samples, no focal amplifications were evident, but some regions, including 11q13, demonstrated segments of duplications or deletions covering entire chromosomes or arms. These samples can be considered as having a simplex amplification pattern. Two samples (7\%) exhibited a complex sawtooth pattern, with several narrow amplifications and deletions throughout the genome. Recurrent genome-wide copy number alterations are reported in Table 2. Copy number alterations identified in $>50 \%$ of 11q13 amplified tumours included gain of 1q, 8p, 8q, loss of $16 \mathrm{q}$ and the distal part of 11q. The combination of 1q gain and 16q loss occurred in 12/29 $(41.4 \%)$ of the tumours. In addition to $11 q 13$, recurrent focal amplicons occurred at $4 \mathrm{q} 13$ (EREG, AREG, RCHY), 8p12, 12q14 (MDM2) and 17q12 (ERBB2). 
Table 2 Frequencies of recurrent copy number alterations among 29 breast tumours with 11q13 amplification (-deletion,+gain, ++amplification).

\begin{tabular}{|c|c|}
\hline Copy number alteration & Frequency \\
\hline $1 \mathrm{p}-$ & $48.3 \%(14 / 29)$ \\
\hline $1 \mathrm{q}+$ & $69.0 \%(20 / 29)$ \\
\hline $3 p 12-21-$ & $34.5 \%(10 / 29)$ \\
\hline $4 q 13+$ & $13.8 \%(4 / 29)$ \\
\hline $6 q-$ & $37.9 \%(11 / 29)$ \\
\hline $8 p 12++$ & $\left.41.4 \%(12 / 29)^{*}\right)$ \\
\hline $8 \mathrm{q}+$ & $51.7 \%(15 / 29)$ \\
\hline $9 p-$ & $48.3 \%(14 / 29)$ \\
\hline $10 q 23-$ & $17.2 \%(5 / 29)$ \\
\hline $11 q-$ & $96.6 \%(28 / 29)$ \\
\hline $12 q 14++$ & $\left.7.0 \%(2 / 29)^{* *}\right)$ \\
\hline $13-$ & $34.5 \%(10 / 29)$ \\
\hline $16 p+$ & $48.3 \%(14 / 29)$ \\
\hline $16 \mathrm{q}-$ & $62.1 \%(18 / 29)$ \\
\hline $17 q 12-21++$ & $17.2 \%(5 / 29)^{* * *)}$ \\
\hline $17 \mathrm{p}-$ & $37.9 \%(11 / 29)$ \\
\hline $18 \mathrm{p}-$ & $37.9 \%(11 / 29)$ \\
\hline $20 q+$ & $37.9 \%(11 / 29)$ \\
\hline $22 q-$ & $37.9 \%(11 / 29)$ \\
\hline
\end{tabular}


Amplification cores and correlation to mRNA expression of 11 113 located genes

When considering the 11q13 region in detail, four different patterns of amplification could be perceived. In 19/29 (66\%) of cases, two or more independent amplicons were evident in concert with a deletion of the remaining q-arm. One continuous amplicon harbouring specific peaks was present in $7 / 29(24 \%)$ of cases, whereas one narrow, specific peak or one continuous amplicon with no specific peaks could be seen in 1/29 (3\%) and 2/29 (7\%) of the cases, respectively. In 28/29 (97\%) of the tumours, amplification at $11 \mathrm{q}$ was followed by deletions at the same chromosomal arm. To identify regions of significant aberrations at 11q13, the GISTIC methodology (Beroukhim et al., 2007) was applied as described below. The resulting chart (Fig 1 a) revealed three main amplification cores with central peaks at $66.9 \mathrm{Mb}, 69.1 \mathrm{Mb}$ and $77.0 \mathrm{Mb}$ respectively. Altogether, the main amplicon covers the range $65-82 \mathrm{Mb}$ that corresponds to cytoband 11q13-q14.1. GISTIC peaks are indicative of regions harbouring driving oncogenes, and were therefore used when candidate genes for expression analyses were selected. Consequently, mRNA expression of RAD9A, S6K2, CCND1, FGF19, FGF4, FGF3, PAK1 and GAB2, was quantified using real-time PCR. The distribution of copy number amplifications/gains in the 11q13-14 region in the 29 samples is presented in Figure 2. To identify possible oncogene candidates, DNA copy number was correlated to relative gene expression using Spearman's Rank Order correlation (Table 3). A significant correlation between gene copy number and mRNA expression levels could be seen for $R A D 9 A, S 6 K 2$, CCND1, PAK1 and GAB2. mRNA expression of FGF19, FGF4 and FGF3 could be detected in $16 / 23,8 / 23$ and $13 / 22$ of the samples, respectively. No significant correlation between gene copy number and mRNA expression was seen for these genes. 

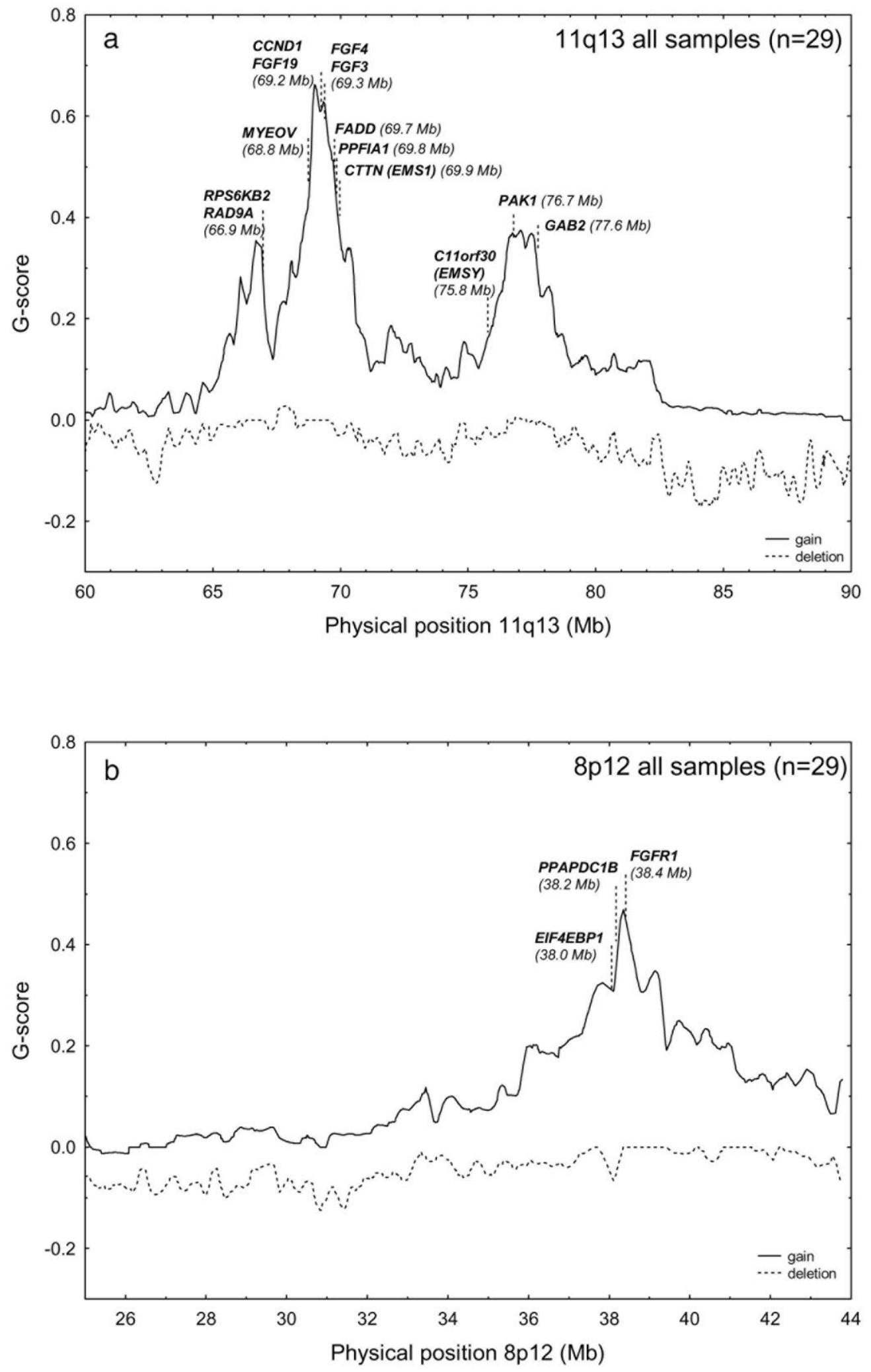

Figure 1 Comprehensive view of the 11q13 amplicon (a) and the 8p12 amplicon (b) and identification of the most significant amplifications, using the principles of GISTIC methodology (Beroukhim et al., 2007). Positions of candidate oncogenes (previously suggested and/or included in the mRNA expression analysis) were received from the human genome build 36 , ver3. 


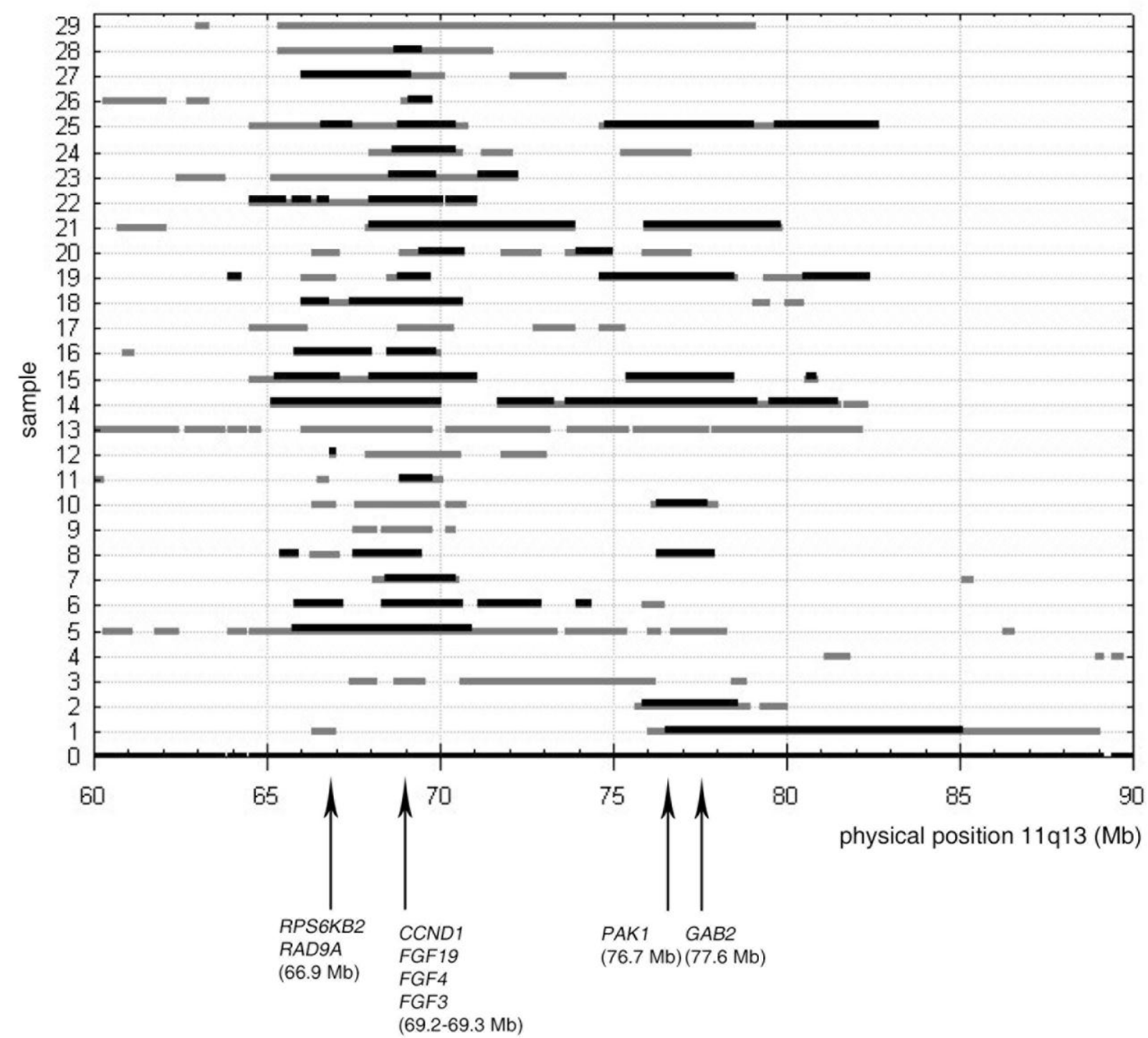

Figure 2 The distribution of copy number amplifications (CNstate $\geq 4$, black bars) and gains (CNstate $\geq 3$, grey bars) in the 11q13-14 region across the 29 samples.

\section{The CCND1 core correlates to ER expression}

Several studies have shown that 11q13 amplification is an event preferably seen in ER positive breast cancers. Consequently, the correlation between ER expression and the three main amplicons at 11q13 according to Figure 1 a, represented by $S 6 K 2, C C N D 1$ and PAK1 gene copy numbers was evaluated. In a multiple regression analysis, only the core encompassing $C C N D 1$ was significantly correlated to ER expression levels ( $66 K 2$ : $\beta=0.15$, $P=0.42 ; C C N D 1: \beta=0.50 P=0.019 ; P A K 1: \beta=-0.16, P=0.40)$. The positive correlation between ER expression and CCND1 copy number could also be seen using Spearman's Rank 
order correlation (Spearman's $\mathrm{R}=0.48 ; \mathrm{P}=0.009$ ). There was no significant connection between ER levels and mRNA expression of any of the 11q13 located genes included (data not shown).

Table 3 Spearman's Rank Order correlation estimating the relationship between mRNA expression and DNA copy number for genes centred in each amplification core at 11q13. DNA copy number was assessed by Affymetrix 250K SNParrays and for $S 6 K 2, C C N D 1$ and PAK1 also with quantitative real-time PCR as previously described (Bostner et al., 2007; Perez-Tenorio et al., 2010). Real-time PCR copy number data for S6K2, CCND1 and PAK1 were also used for the neighbouring genes in respective core (1-3).

\begin{tabular}{|c|c|c|c|c|c|}
\hline & \multicolumn{3}{|c|}{ Array copy number data } & \multicolumn{2}{|c|}{$\begin{array}{c}\text { Real-time PCR copy number } \\
\text { data }\end{array}$} \\
\hline & Gene (11q13) & Spearman R & $\mathrm{p}$-value & Spearman R & $\mathrm{p}$-value \\
\hline \multirow{2}{*}{ Core 1} & $R A D 9 A$ & 0.47 & 0.030 & 0.53 & $0.01^{\text {a) }}$ \\
\hline & $S 6 K 2$ & 0.38 & 0.093 & 0.72 & 0.0001 \\
\hline \multirow{4}{*}{ Core 2} & $C C N D 1$ & 0.61 & 0.003 & 0.67 & 0.0004 \\
\hline & $F G F 19$ & 0.08 & 0.73 & 0.30 & $0.16^{\mathrm{b})}$ \\
\hline & FGF4 & -0.16 & 0.47 & -0.19 & $0.38^{\mathrm{b})}$ \\
\hline & $F G F 3$ & 0.18 & 0.44 & 0.06 & $0.80^{\mathrm{b})}$ \\
\hline \multirow[b]{2}{*}{ Core 3} & $P A K 1$ & 0.69 & 0.0005 & 0.75 & 0.00003 \\
\hline & $G A B 2$ & 0.50 & 0.022 & 0.54 & $0.007^{\mathrm{c})}$ \\
\hline
\end{tabular}

\footnotetext{
a) Copy number data for $S 6 K 2$

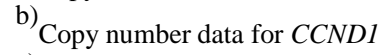

${ }^{\text {c) }}$ Copy number data for $P A K 1$
} 


\section{Prognostic significance of 11q13/8p12 coamplification and coexpression}

In the present study, amplicons in the 8p12 region were found in 55\% (16/29) of the samples of which $41 \%(12 / 29)$ were detected as $\geq 4$ DNA copies. Patterns of amplification were similar to those seen at 11q13, including recurrent loss of the distal part of the p-arm. When applying GISTIC on the 8p12 region, a main peak centred on $38.4 \mathrm{Mb}$ was evident (Fig $\mathbf{1}$ b). In a next step, the 29 samples were divided into two groups based on 8p12 amplification status and GISTIC was applied on the 11q13 region in the two cohorts separately (Fig 3 ). Resulting charts reveal that the most proximal amplicon on 11q13 was exclusively found in the 8 p12 positive group (Fig 3 a) compared to the 8 p12 negative group (Fig $\mathbf{3}$ b). In addition, the distal core is most distinctive in the 8p12 negative group. Consequently, the correlation between the $8 \mathrm{p} 12$ amplicon (here represented by the FGFRl gene) and the three main amplicons at 11q13 according to Figure 1 a, represented by the $C C N D 1(69.1 \mathrm{Mb})$, PAK1 $(76.7 \mathrm{Mb})$ and $S 6 K 2(66.9 \mathrm{Mb})$ genes were investigated. Using multiple linear regression, the proximal amplification core centred on $66.9 \mathrm{Mb}(S 6 K 2)$ correlated significantly to the $8 \mathrm{p} 12$ amplicon, whereas no significant correlation could be seen for the other cores (S6K2: $\beta=0.54$, $P=0.004 ; C C N D 1: \beta=-0.057, P=0.77 ; P A K 1: \beta=-0.13, P=0.47)$.

The impact of amplification on mRNA expression was evaluated for the genes FGFRl, $P P A P D C 1 B$ and $4 E B P 1$, located in the main peak at 8p12 (Fig 1 b). Gene copy number estimated from array data significantly correlated to mRNA expression levels for all these genes (Spearman's Rank Order Correlation FGFR1: R=0.73; $P=0.00015,4 E B P 1: \mathrm{R}=0.53$; $P=0.013$, and $P P A P D C 1 B: \mathrm{R}=0.51 ; P=0.018)$. When the connection between $8 \mathrm{p} 12$ and the proximal amplicon at 11q13 was investigated at the mRNA level, there was a significant correlation between $S 6 K 2$ mRNA levels and the three genes at 8p12 (Table 4). RAD9A mRNA expression was not significantly associated with expression levels of any of the 

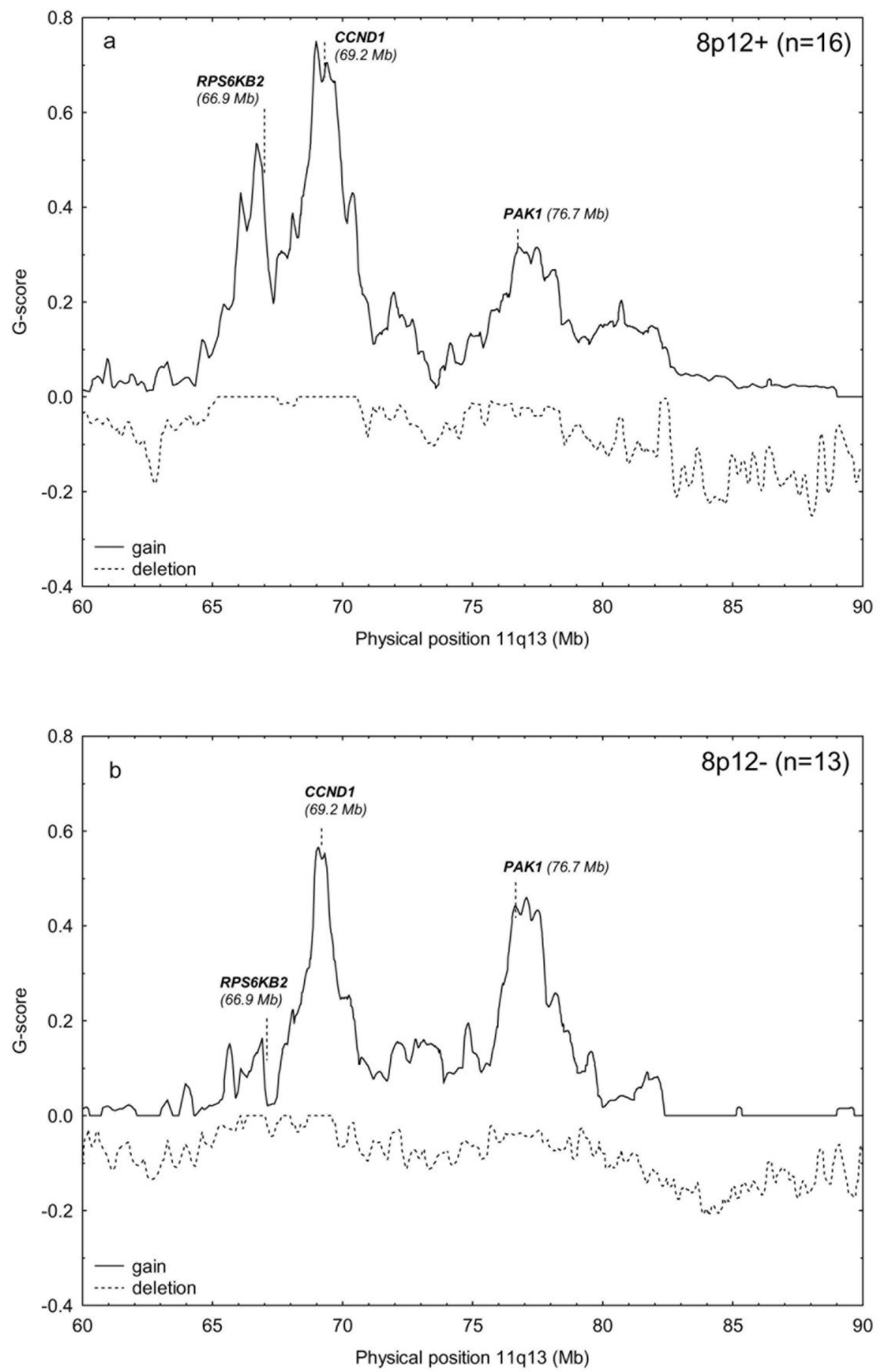

Figure 3 GISTIC view of the 11q13 amplicon in the 29 tumours divided into two groups based on 8p12 status: 8 p12+ $\geq 3$ DNA copies (a), 8p12- < 3 DNA copies (b). 
Table 4 Spearman's Rank Order correlation estimating the relationship between mRNA expression levels for genes centred in each amplification core at $11 \mathrm{q} 13$ versus $8 \mathrm{p} 12$ (significant $\mathrm{p}$-values in bold)

\begin{tabular}{l|lllllll}
\hline \multirow{1}{*}{$\mathbf{8 p 1 2}$} & \multicolumn{3}{c}{$4 E B P 1$} & \multicolumn{3}{c}{ PPAPDC1B } & \multicolumn{2}{c}{ FGFR1 } \\
$\mathbf{1 1 q 1 3}$ & Spearman R & $\mathrm{p}$-value & Spearman R & $\mathrm{p}$-value & Spearman R & p-value \\
\hline & & & & & & & \\
RAD9A & 0.34 & 0.11 & 0.36 & 0.096 & 0.28 & 0.19 \\
S6K2 & $\mathbf{0 . 4 2}$ & $\mathbf{0 . 0 4 4}$ & $\mathbf{0 . 5 2}$ & $\mathbf{0 . 0 1 2}$ & $\mathbf{0 . 4 3}$ & $\mathbf{0 . 0 3 8}$ \\
& & & & & & & \\
CCND1 & 0.34 & 0.11 & 0.27 & 0.21 & 0.41 & 0.052 \\
FGF19 & 0.13 & 0.55 & 0.33 & 0.12 & $\mathbf{0 . 5 1}$ & $\mathbf{0 . 0 1 3}$ \\
FGF4 & 0.0029 & 0.99 & 0.026 & 0.91 & $\mathbf{0 . 4 8}$ & $\mathbf{0 . 0 2 0}$ \\
FGF3 & 0.33 & 0.13 & -0.062 & 0.78 & $\mathbf{0 . 4 8}$ & $\mathbf{0 . 0 2 4}$ \\
& & & & & & \\
PAK1 & 0.027 & 0.90 & 0.34 & 0.11 & 0.18 & 0.41 \\
$G A B 2$ & 0.30 & 0.17 & $\mathbf{0 . 4 3}$ & $\mathbf{0 . 0 4}$ & 0.19 & 0.38 \\
\hline
\end{tabular}

included genes at 8 p12, though a positive trend could be seen. mRNA levels correlated significantly between $F G F R 1$ at $8 \mathrm{p} 12$ and FGF3, FGF4 and FGF19 at the central 11q13 core. There was also a significant relationship between mRNA levels for PPAPDC1B at $8 \mathrm{p} 12$ and $G A B 2$ at the proximal 11q13 core.

Among the 11q13 positive tumours, FGFR1 (8p12) and ERBB2 amplification (17q21) were mutually exclusive events, giving a significant inverse correlation between the number of gene copies (Spearman's Rank R -0.58; $P=0.001$ ). Of the $8 \mathrm{p} 12$ located genes, PPAPDC1B mRNA levels were shown negatively correlated to ERBB2 protein (Spearman's R -0.54, $P=0.0078$ ), whereas a trend was shown for an inverse correlation between $F G F R 1$ mRNA and ERBB2 protein (Spearman's R -0.35, $P=0.099$ ). For $4 E B P 1$ mRNA, no connection to ERBB2 protein levels could be detected (Spearman's R -0.18; $P=0.40$ ). 
In univariate analysis, 8p12 gain/amplification was significantly associated with an increased risk of distant recurrence in the cohort of patients with 11q13 positive tumours (Fig $\mathbf{4} \mathbf{a}$ ). No prognostic significance could be seen for a high PPAPDC1B mRNA expression (Fig $4 \mathbf{b}$ ), but a high expression of FGFRl (Fig 4 c) as well as $4 E B P 1$ mRNA (Fig 4 d) predicted a worse outcome in the patient group. 8p12 gain/amplification and 4EBP1 mRNA expression remained independent prognostic factors when adjusting for tumour size, nodal status and treatments $(8 \mathrm{p} 12 \quad P=0.002 ; P P A P D C 1 B P=0.57 ; F G F R 1$ mRNA $P=0.091 ; 4 E B P 1 \mathrm{mRNA}$ $P=0.0009)$.
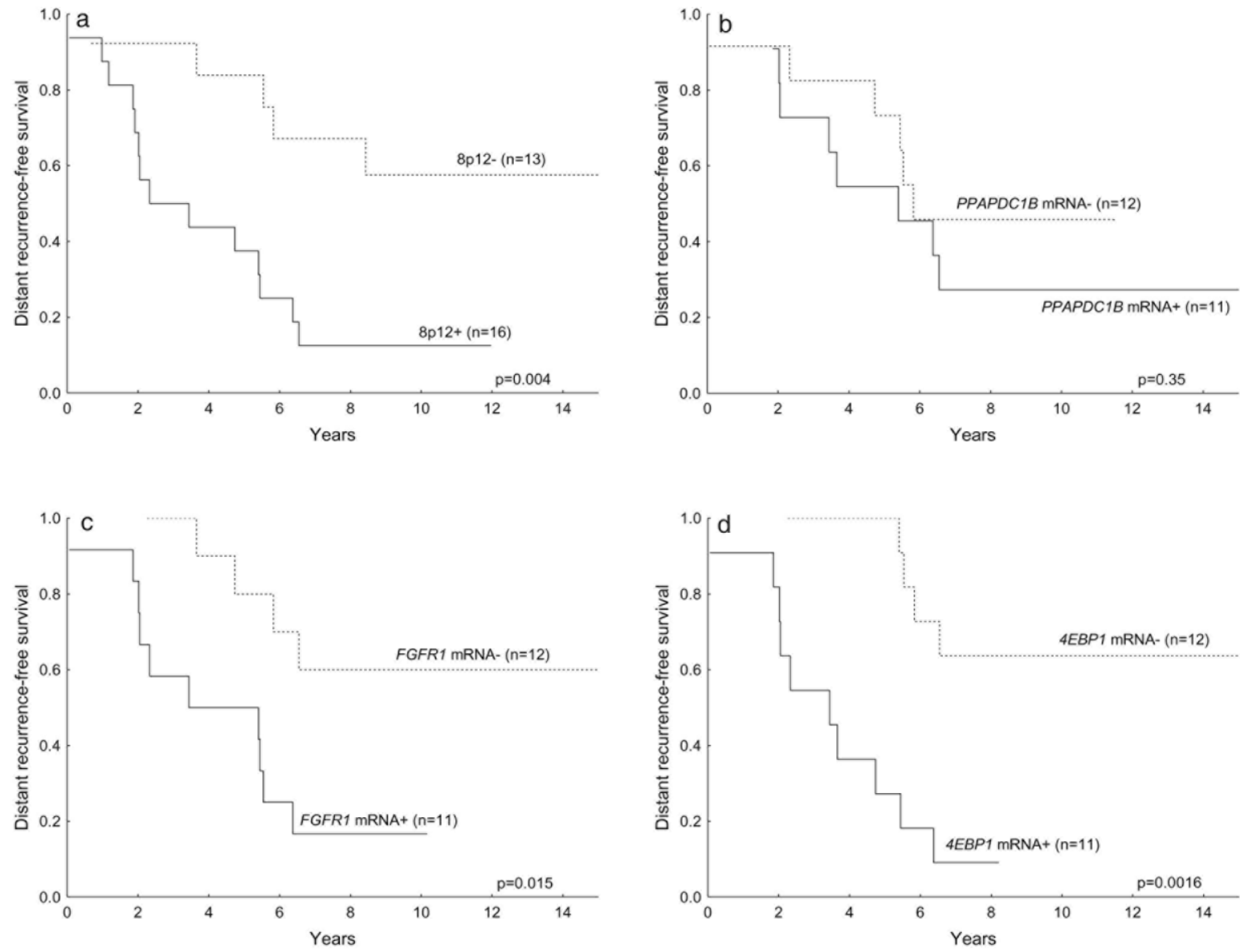

Figure 4 Distant recurrence-free survival among 11q13 positive patients in relation to; 8p12 gain/amplification (8p12+: $\geq 3$ DNA copies, 8p12-: $\leq 2$ DNA copies) (a), high mRNA expression of PPAPDCIB (b), FGFRI (c) and $4 E B P 1$ (d) (the limit for high mRNA levels was defined by the median for each gene). 


\section{Discussion}

In the present study, SNP arrays were used to evaluate the patterns of 11q13 amplification, as well as genome wide copy number alterations, in 29 breast tumours. The array technology allows studies of copy number alterations with a high resolution compared to conventional cytogenetic and PCR methods. Using 250K NspI arrays, the 11q12-14 (60-90Mb) area including approximately 30 million base pairs, is covered by 2400 SNPs, with an average of $12 \mathrm{~kb}$ between each SNP. Previous studies mapping the 11q13 amplicon in breast cancer using FISH, Southern blot, real-time PCR, chromosome CGH and array CGH have suggested four to five independent amplification cores in the area (Karlseder et al., 1994; Bekri et al., 1997; Courjal et al., 1997; Hui et al., 1997; Rodriguez et al., 2004; Kwek et al., 2009). In the present study, several different amplification cores could be detected in the 11q area. The application of GISTIC methodology, allowed summarising DNA copy number changes at $11 \mathrm{q} 13$ across all samples, confirming the $63-82 \mathrm{Mb}$ region as relevant. This also revealed three main areas of significant amplification. The location of the most proximal peak identified (66.9 Mb) differs from earlier studies (Karlseder et al., 1994) (61-63 Mb). It was recently shown that $S 6 K 2$, located in this region, is rarely amplified but commonly displays low level gain in breast tumours (Perez-Tenorio et al., 2010) which could be the reason why this region is identified as relevant by GISTIC, but not with other strategies. Although 11q13 amplifications are heterogeneous, a recurrent feature is deletions at the distal part of 11q, which in turn has been connected to adverse prognosis and a malignant phenotype (Launonen et al., 1998; Laake et al., 1999; Gentile et al., 2001). Studies in squamous cell carcinoma cell lines have suggested that 11q13 amplifications are formed through breakage-fusion-bridge cycles, involving an initiating step where distal 11q is lost (Shuster et al., 2000), which may explain the strong coexistence of 11q13 amplifications and loss of distal 11q in breast cancer. 
The present study showed a significant correlation between gene copy number and mRNA levels of all selected genes in the amplification cores, with the exception of FGF3, FGF4 and FGF19. Regarding $S 6 K 2$, this connection did not reach statistical significance with copy number data from SNP arrays, whereas a strong correlation was found when applying realtime PCR copy number data. In this case, the resolution of the $250 \mathrm{~K}$ SNP arrays on the $S 6 K 2$ area is not perfect and the closest marker is located approximately $35 \mathrm{~kb}$ from the gene, why real-time PCR data is probably more reliable.

A connection between ER positivity and 11q13 amplification in breast cancer has been indicated in several studies (Letessier et al., 2006; Elsheikh et al., 2008) and the present study suggests that a core centred on CCND1 is the most relevant in this context. The expression of CCND1, encoding the cell cycle regulator Cyclin D1 is highly regulated by ER (DoisneauSixou et al., 2003) and in turn, Cyclin D1 can act as an ER activator and induce its transcriptional function by direct binding to the receptor (Fu et al., 2004). However, several genes located at 11q13 are possibly connected to ER pathways. PAK1 gene amplification (Bostner et al., 2007) as well as high protein expression (Holm et al., 2006; Bostner et al., 2010) has been linked to insensitivity to endocrine treatment among breast cancer patients. Also GAB2 expression is suggested to be oestrogen regulated and amplification and overexpression of GAB2 has been reported in breast cancer cell lines and specimens (Daly et al., 2002; Bentires-Alj et al., 2006; Bocanegra et al., 2010). S6K2 in the proximal amplification core, encodes an mTOR regulated serine/threonine kinase, initially identified as a homologue to p70S6 kinase (S6K1) (Gout et al., 1998; Saitoh et al., 1998). In a recent study, gene copy gain and nuclear protein expression of S6K2 were shown to predict tamoxifen response (Perez-Tenorio et al., 2010). Altogether, several genes at 11q13 are potentially connected to ER regulation and signalling. 
It is a well known fact that the 11q13 region is commonly coamplified with regions at $8 \mathrm{p} 11$ 12 in breast cancer and present data suggest that the proximal amplicon at 11q13, harbouring $S 6 K 2$, is the most relevant in this context. Here, three candidate oncogenes in the defined $8 \mathrm{p} 12$ core region were selected for expression analysis based on previous reports (Armengol et al., 2007; Bernard-Pierrot et al., 2008; Turner et al., 2010). Expression of $S 6 K 2$ correlated significantly to expression of both $4 E B P 1$ and $P P A P D C 1 B$. It has been demonstrated that coamplification of $11 \mathrm{q} 13$ and $8 \mathrm{p} 12$ predicts a worse patient outcome than either amplicon alone (Cuny et al., 2000), indicating that genes in the amplicons can promote tumourigenesis in synergy. In accordance with this, although a small group of patients, the present study shows a prognostic relevance of $8 \mathrm{p} 12$ amplification and high expression of the $8 \mathrm{p} 12$ located genes FGFRI and 4EBPI among the patients with 11q13 amplified breast tumours. In breast (Rojo et al., 2007) and ovarian cancer (Castellvi et al., 2006) high expression of phosphorylated 4EBP1 has been correlated to higher grade and poor prognosis. In agreement with several other studies (Ray et al., 2004; Yang et al., 2006; Bernard-Pierrot et al., 2008), the present investigation shows a high correlation between $4 E B P 1$ amplification and increased mRNA expression in breast cancer. Of note, the correlation between $S 6 K 2$ and $4 E B P 1$ expression has also been observed at the protein level (unpublished data). 4EBP1 is generally considered as a tumour suppressor, due to the ability of unphosphorylated protein to inhibit the translational machinery, regulated by mTOR. However, a recent study has shown that MYC decreases the sensitivity to mTOR inhibition and suppresses autophagy by upregulating 4EBP1 expression (Balakumaran et al., 2010). Phoshorylated 4EBP1 has in turn been suggested to be capable of stimulating mTORC1 signalling through binding to the complex (Wang et al., 2006). We recently identified $S 6 K 2$ as a novel candidate oncogene in the 11q13 amplicon, and increased gene copy number was related to a poor outcome among breast cancer patients (Perez-Tenorio et al., 2010). In addition, a functional role of S6K2 
protein in promoting breast cancer cell survival through activation of AKT have been suggested (Sridharan et al., 2011). The results from the present study further emphasize the relevance of $S 6 K 2$ as an interesting candidate oncogene, together with $4 E B P 1$.

FGFR1 was the first reported oncogene in the $8 \mathrm{p} 12$ region, and its amplification and overexpression have been related to poor prognosis and endocrine resistance in breast cancer (Elbauomy Elsheikh et al., 2007; Turner et al., 2010). In the present study FGFR1 mRNA expression was found correlated to expression of the ligands encoded by $F G F 3,4$ and 19 located at the central $11 \mathrm{q} 13$ core. FGF3 and FGF4 were the first suggested potential oncogenes mapped to the 11q13 area, discovered as a result of their role in virus induced mouse mammary tumours. However, the genes were discarded as amplicon drivers in human breast cancer, as they seemed to be transcriptionally inactive (Dickson et al., 1995). In the present study, mRNA expression of FGF3, 4 and 19 could be detected in a substantial proportion of breast tumours and although no significant connection to gene copy number could be seen, tumours with detectable mRNA levels commonly also showed amplification in the area. A role for the FGFs in the 11q13 amplicon may therefore not be excluded. In the cohort of $11 \mathrm{q} 13$ positive tumours, 8p12 and ERBB2 amplification were mutually exclusive events. This is in line with recent data, showing 11q13/8p12 coamplifications to be rare among $E R B B 2$ positive tumours, but common in the ERBB2 negative subgroup, suggesting divergences in cellular pathways driving tumour progression (Staaf et al., 2010). Similar findings were reported recently, when 359 breast cancers where classified into six subtypes based on DNA copy-number aberrations, showing that 11q13/8p12 coamplified cases where enriched in a so called "Amplifier subtype", which in turn did not include any tumours from the HER2 gene-expression subtype (Jönsson et al., 2010). 
In conclusion, SNP arrays have enabled mapping of the 11q13 amplicon in breast tumours with high resolution, revealing several physically independent areas of amplification. With the application of GISTIC methodology, three main core regions could be identified. ER expression is associated with a central core, encompassing CCND1. A proximal 11q13 core including $S 6 K 2$ is for the first time identified as involved in the coamplification with $8 \mathrm{p} 12$, supported by data at both DNA and mRNA levels. In addition, high 4EBP1 mRNA expression seems to predict a poor prognosis among patients with 11q13 amplified breast tumours, suggesting synergy between the mTOR targets S6K2 and 4EBP1 in breast cancer development and progression.

\section{Conflict of interest}

The authors declare no financial conflict of interest related to this work

\section{Acknowledgements}

This study was supported by grants from the Swedish Cancer Foundation and the Swedish Research Council.

\section{References}

Ahnström M, Nordenskjöld B, Rutqvist LE, Skoog L, Stål O. 2005. Role of cyclin D1 in ErbB2-positive breast cancer and tamoxifen resistance. Breast Cancer Res Treat 91:145-151.

Al-Kuraya K, Schraml P, Torhorst J, Tapia C, Zaharieva B, Novotny H, Spichtin H, Maurer R, Mirlacher M, Kochli O, Zuber M, Dieterich H, Mross F, Wilber K, Simon R, Sauter G. 2004. Prognostic relevance of gene amplifications and coamplifications in breast cancer. Cancer Res 64:8534-8540.

Alle KM, Henshall SM, Field AS, Sutherland RL. 1998. Cyclin D1 protein is overexpressed in hyperplasia and intraductal carcinoma of the breast. Clin Cancer Res 4:847-854. Armengol G, Rojo F, Castellvi J, Iglesias C, Cuatrecasas M, Pons B, Baselga J, Ramon y Cajal S. 2007. 4E-binding protein 1: a key molecular "funnel factor" in human cancer with clinical implications. Cancer Res 67:7551-7555. 
Balakumaran BS, Herbert JT, Febbo PG. 2010. MYC activity mitigates response to rapamycin in prostate cancer through 4EBP1-mediated inhibition of autophagy. Autophagy 6:281-282.

Bekri S, Adelaide J, Merscher S, Grosgeorge J, Caroli-Bosc F, Perucca-Lostanlen D, Kelley PM, Pebusque MJ, Theillet C, Birnbaum D, Gaudray P. 1997. Detailed map of a region commonly amplified at 11q13-->q14 in human breast carcinoma. Cytogenet Cell Genet 79:125-131.

Bentires-Alj M, Gil SG, Chan R, Wang ZC, Wang Y, Imanaka N, Harris LN, Richardson A, Neel BG, Gu H. 2006. A role for the scaffolding adapter GAB2 in breast cancer. Nat Med 12:114-121.

Bernard-Pierrot I, Gruel N, Stransky N, Vincent-Salomon A, Reyal F, Raynal V, Vallot C, Pierron G, Radvanyi F, Delattre O. 2008. Characterization of the recurrent 8p11-12 amplicon identifies PPAPDC1B, a phosphatase protein, as a new therapeutic target in breast cancer. Cancer Res 68:7165-7175.

Beroukhim R, Getz G, Nghiemphu L, Barretina J, Hsueh T, Linhart D, Vivanco I, Lee JC, Huang JH, Alexander S, Du J, Kau T, Thomas RK, Shah K, Soto H, Perner S, Prensner J, Debiasi RM, Demichelis F, Hatton C, Rubin MA, Garraway LA, Nelson SF, Liau L, Mischel PS, Cloughesy TF, Meyerson M, Golub TA, Lander ES, Mellinghoff IK, Sellers WR. 2007. Assessing the significance of chromosomal aberrations in cancer: methodology and application to glioma. Proc Natl Acad Sci U S A 104:20007-20012.

Bindels EM, Lallemand F, Balkenende A, Verwoerd D, Michalides R. 2002. Involvement of G1/S cyclins in estrogen-independent proliferation of estrogen receptor-positive breast cancer cells. Oncogene 21:8158-8165.

Bocanegra M, Bergamaschi A, Kim YH, Miller MA, Rajput AB, Kao J, Langerod A, Han W, Noh DY, Jeffrey SS, Huntsman DG, Borresen-Dale AL, Pollack JR. 2010. Focal amplification and oncogene dependency of GAB2 in breast cancer. Oncogene 29:774779.

Borg Å, Sigurdsson H, Clark GM, Fernö M, Fuqua SA, Olsson H, Killander D, McGurie WL. 1991. Association of INT2/HST1 coamplification in primary breast cancer with hormone-dependent phenotype and poor prognosis. Br J Cancer 63:136-142.

Bostner J, Ahnström Waltersson M, Fornander T, Skoog L, Nordenskjöld B, Stål O. 2007. Amplification of CCND1 and PAK1 as predictors of recurrence and tamoxifen resistance in postmenopausal breast cancer. Oncogene 26:6997-7005.

Bostner J, Skoog L, Fornander T, Nordenskjöld B, Stål O. 2010. Estrogen receptor-alpha phosphorylation at serine 305, nuclear p21-activated kinase 1 expression, and response to tamoxifen in postmenopausal breast cancer. Clin Cancer Res 16:1624-1633.

Castellvi J, Garcia A, Rojo F, Ruiz-Marcellan C, Gil A, Baselga J, Ramon y Cajal S. 2006. Phosphorylated 4E binding protein 1: a hallmark of cell signaling that correlates with survival in ovarian cancer. Cancer 107:1801-1811.

Courjal F, Cuny M, Simony-Lafontaine J, Louason G, Speiser P, Zeillinger R, Rodriguez C, Theillet C. 1997. Mapping of DNA amplifications at 15 chromosomal localizations in 1875 breast tumors: definition of phenotypic groups. Cancer Res 57:4360-4367.

Cuny M, Kramar A, Courjal F, Johannsdottir V, Iacopetta B, Fontaine H, Grenier J, Culine S, Theillet C. 2000. Relating genotype and phenotype in breast cancer: an analysis of the prognostic significance of amplification at eight different genes or loci and of p53 mutations. Cancer Res 60:1077-1083.

Daly RJ, Gu H, Parmar J, Malaney S, Lyons RJ, Kairouz R, Head DR, Henshall SM, Neel BG, Sutherland RL. 2002. The docking protein Gab2 is overexpressed and estrogen regulated in human breast cancer. Oncogene 21:5175-5181. 
Dickson C, Fantl V, Gillett C, Brookes S, Bartek J, Smith R, Fisher C, Barnes D, Peters G. 1995. Amplification of chromosome band 11q13 and a role for cyclin D1 in human breast cancer. Cancer Lett 90:43-50.

Doisneau-Sixou SF, Sergio CM, Carroll JS, Hui R, Musgrove EA, Sutherland RL. 2003. Estrogen and antiestrogen regulation of cell cycle progression in breast cancer cells. Endocr Relat Cancer 10:179-186.

Elbauomy Elsheikh S, Green AR, Lambros MB, Turner NC, Grainge MJ, Powe D, Ellis IO, Reis-Filho JS. 2007. FGFR1 amplification in breast carcinomas: a chromogenic in situ hybridisation analysis. Breast Cancer Res 9:R23.

Elsheikh S, Green AR, Aleskandarany MA, Grainge M, Paish CE, Lambros MB, Reis-Filho JS, Ellis IO. 2008. CCND1 amplification and cyclin D1 expression in breast cancer and their relation with proteomic subgroups and patient outcome. Breast Cancer Res Treat 109:325-335.

Fu M, Wang C, Li Z, Sakamaki T, Pestell RG. 2004. Minireview: Cyclin D1: normal and abnormal functions. Endocrinology 145:5439-5447.

Gentile M, Wiman A, Thorstenson S, Loman N, Borg A, Wingren S. 2001. Deletion mapping of chromosome segment 11q24-q25, exhibiting extensive allelic loss in early onset breast cancer. Int J Cancer 92:208-213.

Gout I, Minami T, Hara K, Tsujishita Y, Filonenko V, Waterfield MD, Yonezawa K. 1998. Molecular cloning and characterization of a novel p70 S6 kinase, p70 S6 kinase beta containing a proline-rich region. J Biol Chem 273:30061-30064.

Gunnarsson C, Ahnström M, Kirschner K, Olsson B, Nordenskjöld B, Rutqvist LE, Skoog L, Stål O. 2003. Amplification of HSD17B1 and ERBB2 in primary breast cancer. Oncogene 22:34-40.

Hicks J, Krasnitz A, Lakshmi B, Navin NE, Riggs M, Leibu E, Esposito D, Alexander J, Troge J, Grubor V, Yoon S, Wigler M, Ye K, Borresen-Dale AL, Naume B, Schlicting E, Norton L, Hagerström T, Skoog L, Auer G, Måner S, Lundin P, Zetterberg A. 2006. Novel patterns of genome rearrangement and their association with survival in breast cancer. Genome Res 16:1465-1479.

Holm C, Rayala S, Jirström K, Stål O, Kumar R, Landberg G. 2006. Association between Pak1 expression and subcellular localization and tamoxifen resistance in breast cancer patients. J Natl Cancer Inst 98:671-680.

Hui R, Campbell DH, Lee CS, McCaul K, Horsfall DJ, Musgrove EA, Daly RJ, Seshadri R, Sutherland RL. 1997. EMS1 amplification can occur independently of CCND1 or INT-2 amplification at 11q13 and may identify different phenotypes in primary breast cancer. Oncogene 15:1617-1623.

Hui R, Finney GL, Carroll JS, Lee CS, Musgrove EA, Sutherland RL. 2002. Constitutive overexpression of cyclin D1 but not cyclin E confers acute resistance to antiestrogens in T-47D breast cancer cells. Cancer Res 62:6916-6923.

Jirström K, Stendahl M, Ryden L, Kronblad A, Bendahl PO, Stål O, Landberg G. 2005. Adverse effect of adjuvant tamoxifen in premenopausal breast cancer with cyclin D1 gene amplification. Cancer Res 65:8009-8016.

Jönsson G, Staaf J, Vallon-Christersson J, Ringner M, Holm K, Hegardt C, Gunnarsson H, Fagerholm R, Strand C, Agnarsson BA, Kilpivaara O, Luts L, Heikkilä P, Aittomäki K, Blomqvist C, Loman N, Malmström P, Olsson H, Johannsson OT, Arason A, Nevanlinna H, Barkardottir RB, Borg A. 2010. Genomic subtypes of breast cancer identified by array-comparative genomic hybridization display distinct molecular and clinical characteristics. Breast Cancer Res 12:R42. 
Karlseder J, Zeillinger R, Schneeberger C, Czerwenka K, Speiser P, Kubista E, Birnbaum D, Gaudray P, Theillet C. 1994. Patterns of DNA amplification at band q13 of chromosome 11 in human breast cancer. Genes Chromosomes Cancer 9:42-48.

Kenny FS, Hui R, Musgrove EA, Gee JM, Blamey RW, Nicholson RI, Sutherland RL, Robertson JF. 1999. Overexpression of cyclin D1 messenger RNA predicts for poor prognosis in estrogen receptor-positive breast cancer. Clin Cancer Res 5:2069-2076.

Khoshnoud MR, Löfdahl B, Fohlin H, Fornander T, Stål O, Skoog L, Bergh J, Nordenskjöld B. 2010. Immunohistochemistry compared to cytosol assays for determination of estrogen receptor and prediction of the long-term effect of adjuvant tamoxifen. Breast Cancer Res Treat 126:421-430.

Kwek SS, Roy R, Zhou H, Climent J, Martinez-Climent JA, Fridlyand J, Albertson DG. 2009. Co-amplified genes at 8p12 and 11q13 in breast tumors cooperate with two major pathways in oncogenesis. Oncogene 28:1892-1903.

Laake K, Launonen V, Niederacher D, Gudlaugsdottir S, Seitz S, Rio P, Champeme MH, Bieche I, Birnbaum D, White G, Sztan M, Sever N, Plummer S, Osorio A, Broeks A, Huusko P, Spurr N, Borg A, Cleton-Jansen AM, van't Veer L, Benitez J, Casey G, Peterlin B, Olah E, Borresen-Dale AL, et al. 1999. Loss of heterozygosity at 11q23.1 and survival in breast cancer: results of a large European study. Breast Cancer Somatic Genetics Consortium. Genes Chromosomes Cancer 25:212-221.

Launonen V, Stenback F, Puistola U, Bloigu R, Huusko P, Kytola S, Kauppila A, Winqvist R. 1998. Chromosome 11q22.3-q25 LOH in ovarian cancer: association with a more aggressive disease course and involved subregions. Gynecol Oncol 71:299-304.

Letessier A, Sircoulomb F, Ginestier C, Cervera N, Monville F, Gelsi-Boyer V, Esterni B, Geneix J, Finetti P, Zemmour C, Viens P, Charafe-Jauffret E, Jacquemier J, Birnbaum D, Chaffanet M. 2006. Frequency, prognostic impact, and subtype association of 8p12, 8q24, 11q13, 12p13, 17q12, and 20q13 amplifications in breast cancers. BMC Cancer 6:245.

Ormandy CJ, Musgrove EA, Hui R, Daly RJ, Sutherland RL. 2003. Cyclin D1, EMS1 and $11 q 13$ amplification in breast cancer. Breast Cancer Res Treat 78:323-335.

Perez-Tenorio G, Karlsson E, Waltersson MA, Olsson B, Holmlund B, Nordenskjöld B, Fornander T, Skoog L, Stål O. 2010. Clinical potential of the mTOR targets S6K1 and S6K2 in breast cancer. Breast Cancer Res Treat.

Ray ME, Yang ZQ, Albertson D, Kleer CG, Washburn JG, Macoska JA, Ethier SP. 2004. Genomic and expression analysis of the 8p11-12 amplicon in human breast cancer cell lines. Cancer Res 64:40-47.

Rodriguez C, Hughes-Davies L, Valles H, Orsetti B, Cuny M, Ursule L, Kouzarides T, Theillet C. 2004. Amplification of the BRCA2 pathway gene EMSY in sporadic breast cancer is related to negative outcome. Clin Cancer Res 10:5785-5791.

Rojo F, Najera L, Lirola J, Jimenez J, Guzman M, Sabadell MD, Baselga J, Ramon y Cajal S. 2007. 4E-binding protein 1, a cell signaling hallmark in breast cancer that correlates with pathologic grade and prognosis. Clin Cancer Res 13:81-89.

Rudas M, Lehnert M, Huynh A, Jakesz R, Singer C, Lax S, Schippinger W, Dietze O, Greil R, Stiglbauer W, Kwasny W, Grill R, Stierer M, Gnant MF, Filipits M. 2008. Cyclin D1 expression in breast cancer patients receiving adjuvant tamoxifen-based therapy. Clin Cancer Res 14:1767-1774.

Saitoh M, ten Dijke P, Miyazono K, Ichijo H. 1998. Cloning and characterization of p70(S6K beta) defines a novel family of p70 S6 kinases. Biochem Biophys Res Commun 253:470-476. 
Schuuring E. 1995. The involvement of the chromosome 11q13 region in human malignancies: cyclin D1 and EMS1 are two new candidate oncogenes--a review. Gene 159:83-96.

Shuster MI, Han L, Le Beau MM, Davis E, Sawicki M, Lese CM, Park NH, Colicelli J, Gollin SM. 2000. A consistent pattern of RIN1 rearrangements in oral squamous cell carcinoma cell lines supports a breakage-fusion-bridge cycle model for 11q13 amplification. Genes Chromosomes Cancer 28:153-163.

Simpson JF, Quan DE, O'Malley F, Odom-Maryon T, Clarke PE. 1997. Amplification of CCND1 and expression of its protein product, cyclin D1, in ductal carcinoma in situ of the breast. Am J Pathol 151:161-168.

Sridharan S, Basu A. 2011. S6 Kinase 2 Promotes Breast Cancer Cell Survival via Akt. Cancer Res Mar 22 [Epub ahead of print].

Staaf J, Jonsson G, Ringner M, Vallon-Christersson J, Grabau D, Arason A, Gunnarsson H, Agnarsson BA, Malmstrom PO, Johannsson OT, Loman N, Barkardottir RB, Borg A. 2010. High-resolution genomic and expression analyses of copy number alterations in HER2-amplified breast cancer. Breast Cancer Res 12:R25.

Stendahl M, Kronblad A, Ryden L, Emdin S, Bengtsson NO, Landberg G. 2004. Cyclin D1 overexpression is a negative predictive factor for tamoxifen response in postmenopausal breast cancer patients. Br J Cancer 90:1942-1948.

Stål O, Sullivan S, Sun XF, Wingren S, Nordenskjöld B. 1994. Simultaneous analysis of cerbB-2 expression and DNA content in breast cancer using flow cytometry. Cytometry 16:160-168.

Turner N, Pearson A, Sharpe R, Lambros M, Geyer F, Lopez-Garcia MA, Natrajan R, Marchio C, Iorns E, Mackay A, Gillett C, Grigoriadis A, Tutt A, Reis-Filho JS, Ashworth A. 2010. FGFR1 amplification drives endocrine therapy resistance and is a therapeutic target in breast cancer. Cancer Res 70:2085-2094.

Wang L, Rhodes CJ, Lawrence JC, Jr. 2006. Activation of mammalian target of rapamycin (mTOR) by insulin is associated with stimulation of 4EBP1 binding to dimeric mTOR complex 1. J Biol Chem 281:24293-24303.

Weinstat-Saslow D, Merino MJ, Manrow RE, Lawrence JA, Bluth RF, Wittenbel KD, Simpson JF, Page DL, Steeg PS. 1995. Overexpression of cyclin D mRNA distinguishes invasive and in situ breast carcinomas from non-malignant lesions. Nat Med 1:1257-1260.

Wilcken NR, Prall OW, Musgrove EA, Sutherland RL. 1997. Inducible overexpression of cyclin D1 in breast cancer cells reverses the growth-inhibitory effects of antiestrogens. Clin Cancer Res 3:849-854.

Wrange O, Nordenskjöld B, Gustafsson JA. 1978. Cytosol estradiol receptor in human mammary carcinoma: an assay based on isoelectric focusing in polyacrylamide gel. Anal Biochem 85:461-475.

Yang ZQ, Streicher KL, Ray ME, Abrams J, Ethier SP. 2006. Multiple interacting oncogenes on the 8p11-p12 amplicon in human breast cancer. Cancer Res 66:11632-11643. 